\title{
PENGEMBANGAN MODEL KEGIATAN SENTRA BERMAIN DALAM MENGEMBANGKAN KREATIVITAS ANAK USIA DINI
}

\author{
YULIANI NURANI ${ }^{1}$ TRIAS MAYANGASRI ${ }^{2}$ \\ Pendidikan Guru Pendidikan Anak Usia Dini (PGPAUD) \\ Universitas Negeri Jakarta \\ Email: yuliani.nurani@gmail.com
}

\begin{abstract}
The objective of the research is to develop children activities in play center for encourage kindergarten children's creativity in special region Jakarta. This study used Research and Development design consisting 3 (three) stages: pre-development, developmental stage, and applying the model to examine the effectivity. This research conducted in April-June 2016.The first trial is conducted in TK Al-Jannah East Jakarta which involved 18 children. The second trial is conducted in TK Mutiara Kasih Bogor Citywhich involved 16 children. When conducting the survey, purposive sampling is used to obtain the kindergarten which are approriate with the objective of the research. The research found that the implementation of model of center play activities can develop early childhood creativity. Children creativity develop properly through the development of play activity in sentra model. Several variants of play activities which developed in this research, it can implement to foster children creativity in learning practices.
\end{abstract}

Keywords: Creativity, Play Center, Kindergarten.

\begin{abstract}
Abstrak:Penelitian ini bertujuan untuk mengembangkan model kegiatan di sentra bermain dalam rangka mengembangkan kreativitas anakTK di DKI Jakarta. Penelitian ini menggunakan desain Researchand Development yang terdiri dari tiga tahapan, yaitu tahap pra-pengembangan, tahapan pengembangan dan tahap penerapan untuk menguji efektivitasnya. Penelitian ini dilaksanakan bulan April-Juni2016. Uji coba model pertama dilakukan di TK Al-Jannah Jakarta Timur dengan jumlah 18 anak. Uji coba model kedua dilakukan diTK Mutiara Kasih Kota Bogor dengan jumlah 16 anak.Ketika melakukan survey, teknik purpossive sampling digunakan untuk menentukan TK yang sesuai dengan kriteria penelitian.Hasil penelitian mengungkapkanimplementasi model kegiatan bermain sentra dapat mengembangkan kreativitas anak usia dini.Beberapa varian kegiatan bermain yang telah dikembangkan dalam penelitian ini, dapat digunakan dalam praktik pengembangan kreativitas anak.
\end{abstract}

Kata kunci: Kreativitas, Sentra Bermain, Taman Kanak-kanak.

\section{PENDAHULUAN}

Menjadi anak yang sehat, cerdas, ceria, dan berakhlak mulia adalah dambaan semua orangtua yang memiliki anak usia dini. Selain itu, anak perlu juga mengoptimalkan kreativitasnya agar dapat bermanfaat baik untuk dirinya sendiri, orang tua, masyarakat.

Berbagai potensi tersebut antara lain potensi kecerdasan, potensi keberbahasaan, potensi fisik hingga potensi yang terkait dengan kreativitas Mayesty (1990:122). 
Untuk menumbuhkembangkan agar anak menjadi kreatif sangat tergantung pada kemampuan orang di sekitarnya, termasuk kondisi lingkungan sekitar dimana anak hidup.

Kreativitas anak usia dini pada dasarnya dapat dikembangkan dengan berbagai cara, baik yang dilakukan oleh orangtua maupun guru disekolah. Berkaitan dengan peran guru di sekolah, khususnya di taman kanak-kanak, maka dibutuhkan berbagai pendekatan dan strategi pembelajaran yang dapat mengembangkan kreativitas anak. Salah satu strategi pembelajaran yang saat ini diakui sebagai suatu strategi yang berpihak pada tumbuh kembang dan tahapan cara berpikir anak adalah strategi pembelajaran berbasis sentra bermain. Salah satu usaha pengembangan kreativitas anak yaitu melalui beragam kegiatan di sentra bermain. Sentra adalah model pembelajaran yang memiliki ciri khas: learning by doing, dimana anak terlibat langsung dalam pembelajaran; learning by stimulating, dimana pembelajaran anak diberikan sesuai dengan tahapan perkembangannya; dan learning by modeling, dimana pembelajarannya menggunakan orang dewasa serta anak yang perkembangnya lebih berkembang. Terdapat beberapa Taman Kanak-Kanak (TK) yang menggunakan pendekatan pembelajaran berbasis sentra bermain. Pembelajaran sentra sangat menarik bagi anak. Anak dapat memilih kegiatan pembelajaran sesuai dengan keinginan atau minat yang dimiliki. Sentra merupakan suatu pusat kegiatan belajar atau pusat sumber belajar yang merupakan suatu wahana yang sengaja dirancangkan untuk menstimulasi berbagai aspek perkembangan pada anak usia dini. Istilah lain sentra, yaitu area, sudut kegiatan anak dan pusat minat (Catron dan Allen, 1999).

Berdasarkan hasil analisis terdapat guru sentra yang masih kurang menyiapkan media atau kegiatan yang bervariasi dalam proses pembelajaran. Peraturan Menteri Pendidikan dan Kebudayaan (Permendikbud) No 146 tahun 2014 menyatakan bahwa guru seharusnya 
Pengembangan Model Kegiatan Sentra... Yuliani \& Trias

memanfaatkan lingkungan dan memilih alat bermain dan sumber belajar yang ada di lingkungan. Media tidak hanya sebagai alat bantu bagi guru untuk mengajar, melainkan juga sebagai alat bantu dalam menyampaikan pesan pembelajaran. Media merupakan alat yang digunakan untuk menunjang kegiatan proses pembelajaran. Akan tetapi, guru hanya menggunakan satu media dalam proses pembelajaran, sehingga membuat anak merasa bosan dan tidak adanya dorongan untuk memunculkan ide kreatif (Laporan PPL Mahasiswa S1 PG PAUD FIP UNJ, 2016)

Masyarakat awam di Indonesia sampai saat ini masih terdapat pandangan yang keliru dalam mendefinisikan kecerdasan. Kecerdasan dianggap sebagai sesuatu yang tunggal. Seorang anak dikatakan cerdas jika ia memiliki kecakapan menonjol dalam bidang bahasa dan matematis. Sebagai contoh, seorang anak yang berhasil memperoleh skor tinggi dalam tes yang mengukur kecerdasan matematis dan bahasa dikatakan lebih cerdas dibandingkan anak yang mampu menari dengan lemah gemulai, mampu bermain musik, terampil dalam berolah tubuh atau anak yang peka pada suara hewan yang terdapat di lingkungan sekitarnya. Sebagian besar anak tersebut di atas tidak menerima penguatan di lembaga pendidikan, seolah mereka tidak dapat dibanggakan dan kurang dihargai. (Laporan PPL Mahasiswa S1 PG PAUD FIP UNJ, 2016)

Berdasarkan latar belakang masalah yang telah dikemukakan, penelitian ini menyampaikan rumusan masalah "Bagaimana penggunaan model kegiatan sentra bermain dapat mengembangkan kreativitas anak usia dini?"”

Adapun tujuan dari penelitian ini adalah sebagai berikut: Mengembangkan model kegiatan bermain sentra yang dapat mengembangkan kreativitas anak. (2) Mendeskripsikan proses pengembangan kreativitas pada anak usia dini.

Menelaah efektivitas pengembangan model kegiatan sentra bermain dalam membangun kreativitas anak usia dini. 


\section{METODE PENELITIAN}

Penelitian ini menggunakan desain Research \& Development untuk menghasilkan produk dan menguji keefektifan produk tersebut.

Tahapan dalam penelitian ini diadaptasi dari sepuluh langkah penelitian dan pengembangan sebagaimana dikemukakan Borg dan Gall (1983: 267). Metode ini dipilih sesuai dengan sasaran dan tujuan akhir penelitian ini yang ditujukan untuk menemukan serta mengembangkan model kegiatan bermain sentra menjadi model yang dapat dipergunakan sebagai alternatif pembelajaran pada lembaga PAUD.

\section{Tempat dan Waktu Penelitian}

Penelitian dilakukan di 2 (dua) TK, yaitu TK Al-Jannah yang berada di Jakarta Timur dan TK Mutiara Kasih yang berada di Kota Bogor

\section{Populasi dan Sampel}

Populasi dalam penelitian ini adalah anak-anak yang sedang mengikuti pendidikan di Taman Kanak-kanak, yaitu pada kelompok B usia 5-6 tahun yang berada di DKI Jakarta dan Jawa Barat; Sedangkan sampel yang digunakan adalah 18 anak dari TK Al-Jannah Jakarta Timur dan 16

anak dari TK Mutiara Kasih Kota Bogor.

\section{HASIL DAN PEMBAHASAN}

Deskripsi Hasil

Pra-

Pengembangan

Pemaparan data hasil penelitian pendahuluan melalui kuesioner yang dilaksanakan berdasarkan purposive sampling atau sampel bertujuan yang bersifat penyesuaian berkelanjutan dari urutan butir pertanyaan yang diajukan. Penyebaran kuesioner dilakukan pada 5 (lima) wilayah di Provinsi DKI Jakarta, dengan menyebarkan 150 kuesioner untuk 30 lembaga TK. Kuesioner yang kembali hanya berjumlah 135 lembar.

Berdasarkan hasil studi
pendahuluan tentang kondisi awal
penggunaan kegiatan bermain di
sentra ditemukan bahwa terdapat
$86 \%$ guru yang belum menggunakan
sentra bermain dalam meningkatkan
kreativitas anak usia dini dalam
pembelajaran, dengan alasan: (1)
$81 \%$ belum tahu manfaat, dan (3)
$87 \%$ adanya kecemasan dari segi
biaya bahwa dengan membuat sentra


Pengembangan Model Kegiatan Sentra... Yuliani \& Trias

bermain membutuhkan biaya yang mahal.Dengan demikian, berarti pengembangan kreativitas anak melalui kegiatan di sentra bermain masih diperlukan dalam rangka meningkatkan kreativitas pada anak usia dini di Lembaga PAUD umumnya dan TK khususnya.

\section{Deskripsi Hasil Pengembangan}

\section{Sentra Bermain}

Berdasarkan tujuan

penelitian, maka pada tahap pengembangan model telah dihasilkan (1) pengembangan model konseptual sentra bermain dan (2) pengembangan desain sentra bermain yang dapat meningkatkan kreativitas anak usia dini.
Dalam proses kerjanya kedua produk pengembangan ini bersifat hirarkial dan saling berkesinambungan. Artinya, pada langkah awal dikembangkan model konseptual sentra bermain, kemudian langkah berikutnya dikembangkan desain sentra bermain yang dapat meningkatkan kreativitas anak.

Pengembangan Model Konseptual Sentra Bermain

Model konseptual sentra bermain yang dibuat sesuai dengan tujuan program kegiatan bermain berupa kompetensi dasar dan indikator. Selain berdasarkan tujuan, dalam pengembangan sentra bermain diarahkan pada unsur efektifitas pencapaian tujuan pembelajaran. Berikut ini adalah bagan model konseptual sentra bermain. 
JURNAL PENDIDIKAN USIA DINI

Volume 11 Edisi 2, November 2017

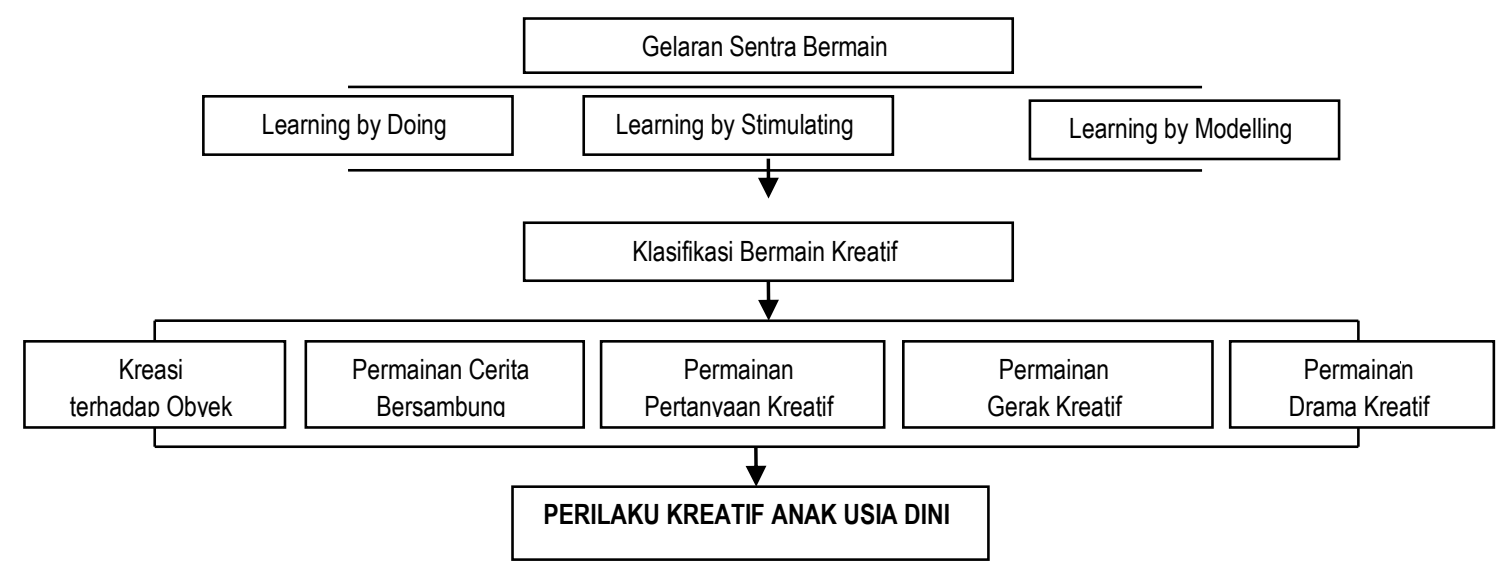

Bagan 1 : Pengembangan Model

Konseptual Sentra Bermain

Selanjutnya dalam proses pembelajaran (learning process), media gelaran sentra berupa bahan belajar dan bermain berfungsi sebagaipengantar pesan atau sumber belajar yang dapat membantu tercapainya tujuan program pembelajaran.

Pengembangan model konseptual sentra bermain dikembangkan dengan mengintegrasikan 3 (tiga) jenis kegiatan pembelajaran, yaitu learning by doing, learning by stimulating, dan learning by modelling didalam pembelajaran pada sentra bermain.
Kegiatan sentra bermain yang dikembangkan adalah media yang dapat digunakan dalam kegiatan bermain yang berbasis kerja (learning by doing), kegiatan bermain yang berbasis stimulasi (learning by stimulation) dan kegiatan bermain yang berbasis contoh/teladan (learning by modelling). Selanjutnya pada setiap sentra bermain dikembangkan berbagai kegiatan berdasarkan klasifikasi bermain kreatif, yaitu kreasi terhadap obyek, permainan cerita bersambung, permainan pertanyaan kreatif, permainan gerak kreatif dan permainan drama kreatif. 
Pengembangan Model Kegiatan Sentra... Yuliani \& Trias

\section{Pengembangan Desain Sentra}

\section{Bermain}

Kegiatan yang dilakukan di setiap tahapan berdasarkan istilah terkini dalam pengembangan kurikulum anak usia dini, yaitu: (1) Pengembangan Proyek Tema, (2) Pengembangan Keterpaduan Proyek Tema dengan Klasifikasi Bermain Kreatif, (3) Pengembangan Keterpaduan Tema dan Indikator, (4) Pengembangan Pengembangan Materi: Bahan Belajar dan Bermain, (5) Pengembangan Desain dan Produksi Media Sentra Bermain, (6) Pengembangan

Asesmen

Perkembangan, (7) Pengembangan Strategi Pembelajaran sehingga menjadi satu kesatuan yang utuh dalam sistem pembelajaran gelaran sentra bermain pada anak usia dini.

\section{Seperangkat Kegiatan di Sentra} Bermain

Adapun sentra bermain yang dikembangkan, yaitu sentra bermain peran dan sentra seni. Selanjutnya dikembangkan strategi pembelajaran yang memiliki 4 komponen, yaitu: (a) Urutan kegiatan pembelajaran, yaitu urutan kegiatan yang dilakukan oleh guru bersama anak, mulai dari kegiatan di awal (penyambutan kedatangan anak, jurnal pagi dan appersepsi); kegiatan inti (pengalaman belajar yang didapat oleh anak berdasarkan indikator) serta kegiatan penutup (jurnal siang, review kegiatan dan umpan balik serta salam penutupan);

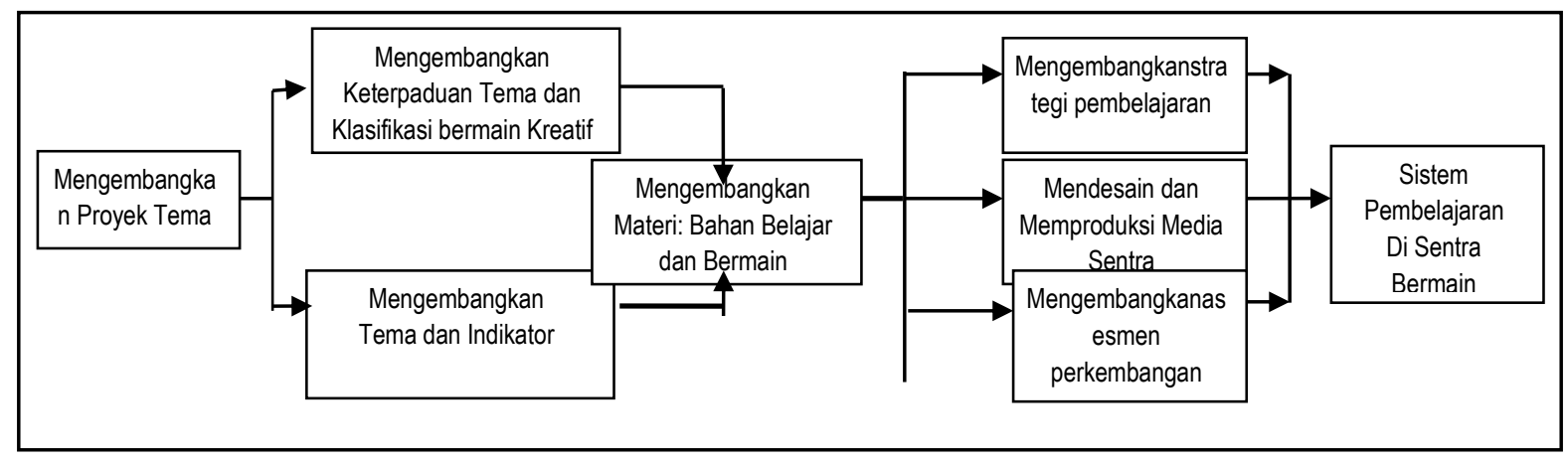

Bagan 2 : Desain Pembelajaran pada Sentra Bermain 
(b) Metode pembelajaran, yaitu cara guru mengorganisasikan materi dan anak agar terjadi proses belajar yang efektif dan efisien. Berkaitan dengan desain pembelajaran ini, metode yang digunakan adalah praktek langsung, bercakap-cakap, bercerita, berdiskusi, resitasi, simulasi, demonstrasi/peragaan, percobaan dan bermain peran; (c) Media pembelajaran, yaitu peralatan dan bahan pembelajaran yang akan digunakan oleh anak dan guru selama kegiatan belajar berlangsung. Adapun media yang digunakan dalam desain ini adalah media yang sengaja dirancang khusus sesuai dengan tema Aku dan Keluargaku, terdiri dari media langsung (bendabenda konkrit), media cetak, media elektronik (tape dan kaset), media buatan guru dan media sebagai hasil karya anak sendiri; (d) Alokasiwaktu, yaitu alokasi yang disediakan untuk anak melakukan kegiatan belajar dalam rangka menyelesaikan setiap langkah. Alokasi waktu yang tersedia adalah 1 jam 50 menit (dari pukul 8.20-10.10). Alokasi waktu tidak ditentukan oleh guru berdasarkan urutan kegiatan secara kaku, tetapi bersifat fleksibel sesuai dengan keberminatan anak serta laju dan kecepatan belajar setiap anak.

$$
\text { Pengembangan strategi }
$$

pembelajaran ini tampak jelas dan tertulis pada Rencana Pelaksanaan Pembelajaran Harian (RPPH) Matrik berikut ini adalah sebaran isi/materi/kegiatan bermain yang diharapkan dapat meningkatkan kreativitas anak.

\section{Matriks}

Sebaran Isi / Materi /

Kegiatan di Sentra Bermain

\begin{tabular}{|c|c|}
\hline $\begin{array}{c}\text { Minggu/ } \\
\text { hari }\end{array}$ & $\begin{array}{l}\text { Kegiatan di Sentra } \\
\text { Bermain }\end{array}$ \\
\hline M1 / H1 & $\begin{array}{l}\text { Gerak bebas mengikuti } \\
\text { irama lagu "burung } \\
\text { kakak tua, finger } \\
\text { painting "stempel } \\
\text { tanganku", "cerita } \\
\text { flannel "anggota } \\
\text { keluarga", doa untuk } \\
\text { ayah-ibu, tepuk tangan } \\
\text { sambil menyanyikan } \\
\text { lagu "kasih ibu" }\end{array}$ \\
\hline M1 / H 2 & $\begin{array}{l}\text { Remas dan tempel } \\
\text { "bingkai fotoku", } \\
\text { Kantong } \\
\text { "perlengkapan anak, ibu } \\
\text { dan ayah", big book } \\
\text { "keluarga sakinah", } \\
\text { berpantomim "gaya } \\
\text { ayah dan ibu" }\end{array}$ \\
\hline M1 / H3 & $\begin{array}{l}\text { Finger painting "bibir } \\
\text { merahku", gerak fisik } \\
\text { berlari "jepit } \\
\text { menggelitik", syair lagu } \\
\text { "kasih ibu", mengenal }\end{array}$ \\
\hline
\end{tabular}


Pengembangan Model Kegiatan Sentra...

Yuliani \& Trias

\begin{tabular}{|c|c|}
\hline & $\begin{array}{l}\text { identitas diri melalui } \\
\text { "foto diri", }\end{array}$ \\
\hline $\mathrm{M} 2 / \mathrm{H} 1$ & $\begin{array}{l}\text { Makanan sehat dan } \\
\text { halal, fun cooking } \\
\text { "wajah di rotiku", syair } \\
\text { "potong roti", ekspresi } \\
\text { gerakan sesuai irama } \\
\text { lagu. }\end{array}$ \\
\hline $\mathrm{M} 2 / \mathrm{H} 2$ & $\begin{array}{l}\text { Minuman kesukaanku, } \\
\text { takaran alamiah, } \\
\text { membuat susu sendiri, } \\
\text { lagu "aneka rasa", doa } \\
\text { sebelum makan }\end{array}$ \\
\hline $\mathrm{M} 2 / \mathrm{H} 3$ & $\begin{array}{l}\text { Bermain bola } \\
\text { "menangkap dan } \\
\text { melempar", pengamatan } \\
\text { langsung "buah dan } \\
\text { sayuran", menempel } \\
\text { "strawberry", syair dan } \\
\text { lagu "papaya cha-cha". }\end{array}$ \\
\hline M3 / H1 & $\begin{array}{l}\text { Berjalan lurus dengan } \\
\text { membawa gelas berisi } \\
\text { air, papan display } \\
\text { "kebersihan } \\
\text { lingkungan", percobaan } \\
\text { sederhana "wah..banjir" } \\
\text {, doa selamat, bermain } \\
\text { alat musik sederhana } \\
\text { "botol ajaib". }\end{array}$ \\
\hline M3 / H2 & $\begin{array}{l}\text { Alat mandiku, cerita } \\
\text { seri "kebersihan diri", } \\
\text { mewarnai gambar, } \\
\text { mengekspresikan } \\
\text { gerakan sesuai irama } \\
\text { lagu "ayo mandi". }\end{array}$ \\
\hline M3 / H3 & $\begin{array}{l}\text { Peralatan makan, media } \\
\text { langsung "makan gizi } \\
\text { seimbang", menjahit } \\
\text { alas makan, tata cara } \\
\text { makan, lagu "makan } \\
\text { jangan bersuara" dan } \\
\text { "ayo makan bersama", } \\
\text { kalimat thoyibah } \\
\text { "alhamdullilah". }\end{array}$ \\
\hline M4 / H1 & $\begin{array}{l}\text { Senam fantasi dengan } \\
\text { lagu "bangun tidur }\end{array}$ \\
\hline
\end{tabular}

\begin{tabular}{|c|c|}
\hline & $\begin{array}{l}\text { kuterus mandi", toilet } \\
\text { training, gambar seri } \\
\text { "kegiatan pagi, siang } \\
\text { dan malam hari", kipas } \\
\text { untuk ibuku, doa } \\
\text { bangun tidur. }\end{array}$ \\
\hline M4 / H2 & $\begin{array}{l}\text { Mari mengenal air, } \\
\text { Praktek menyikat gigi, } \\
\text { bermain peran "ke } \\
\text { dokter gigi", bermain } \\
\text { kuda bisik. }\end{array}$ \\
\hline M4 / H3 & $\begin{array}{l}\text { Siapa cepat dia menang } \\
\text { "memakai kaos kaki } \\
\text { dan sepatu, memakai } \\
\text { baju sendiri, finger } \\
\text { painting "rambutku". }\end{array}$ \\
\hline
\end{tabular}

Setiap kegiatan dan media yang dikembangkan pada sentra bermain peran dan musik dibuat berdasarkan indikator yang telah ditentukan diawal pembelajaran.

\section{Deskripsi Hasil Penerapan}

Berdasarkan hasil asesmen perkembangan anak pada uji lapangan pengembangan kreativitas anak usia dini melalui kegiatan di sentra bermain, terdapat 12 dari 18 anak atau 66,8 \% yang memiliki katagori berkembang dan konsisten kemampuannya yang ditunjukkan melalui kumpulan hasil perkembangan anak dalam bentuk satu set berkas portofolio yang berisi karya/ produk dan atau perilaku 
nyata yang teramati (observable) dan dapat terukur (measureable). Itu berarti seperangkat kegiatan di sentra bermain yang digunakan dalam program kegiatan bermain yang telah dirancang dan dikembangkan secara sistematis dapat meningkatkan penguasaan anak terhadap pencapaian indikator perkembangan yang menjadi tolok ukur keberhasilan dari program kegiatan bermain ini.

Terdapat penerapan secara konkrit seluruh indikator dari aspek kreativitas yang muncul pada saat kegiatan bermain yang diklaksifikasikan dalam 5 (lima) jenis permainan dan diidentikkan dengan bentuk permainan, yaitu kreasi terhadap objek, permainan dalam cerita bersambung, permainan drama kreatif, permainan gerak kreatif dan permainan dalam pertanyaan kreatif.

\section{Analisis Hasil Temuan Penelitian}

Berdasarkan hasil studi literatur dan penelitian pendahuluan melalui penyebaran kuesioner dan studi dokumentasitentang kondisi awal penggunaan media gelaran sentra bermain ditemukan bahwa terdapat $86 \%$ guru yang belum menggunakan sentra bermain dalam meningkatkan kreativitas dini pada pembelajaran di TK. Itu berarti pengembangan kegiatan sentra bermain perlu terus dilanjutkan.

$$
\text { Pengembangan sentra }
$$

bermain telah menghasilkan model konseptual dan desain pengembangan media yang sesuai dengan konsep pembelajaran anak usia dini. Selain itu, sejumlah kegiatan di setiap gelaran sentra telah dikembangkan berdasarkan klasifikasi bermain kreatif, yaitu kreasi terhadap obyek, permainan cerita bersambung, permainan pertanyaan kreatif, permainan gerak kreatif, dan permainan drama kreatif.

Pembahasan Hasil Temuan Penelitian

Berdasarkan hasil pengembangan kreativitas anak usia dini melalui kegiatan di sentra bermain dan kajian teori secara sistematis serta terencana, dapat hasil temuan sebagai berikut.

$$
\text { Pengembangan model }
$$
konseptual sentra bermain bagi anak usia dini telah sesuai dengan fokus utama yaitu pengembangan kegiatan 
Pengembangan Model Kegiatan Sentra... Yuliani \& Trias

sentra bermain. Artinya, melalui kegiatan pada sentra bermain yang dikembangkan dalam penelitian ini, sejumlah karakteristik program kegiatan bermain kreatif terlaksana dengan baik. Pengembangan ini sesuai dengan prosedur dikemukakan oleh para ahli anak usia dini yang dirumuskan oleh National Association for Early Childhood and Young Children.

Kegiatan bermain telah dikembangkan berdasarkan tahapan, tugas dan karakteristik perkembangan anak usia 3-6 tahun ternyata mampu mengoptimalkan aspek kreativitas khususnya produk dan proses, menggunakan pendekatan yang berpusat pada anak, yang ditandai dengan interaksi dinamis antara guru dengan anak dan atau antara anak dengan anak lainnya. Hal tersebut diatas telah berdampak pada kegiatan bermain kreatif dimana terdapat keterlibatan anak secara aktif dan totalitas, lebih mementingkan proses daripada hasil, terbebas dari aturan yang mengikat dan telah dilakukan melalui kegiatan nyata atau sesungguhnya (Kitano dan Kirby (1986:127-167); Bennett, Finn
\& Cribb Bennett, Finn Jr dan Cribb, (1999:91-100); Bredekamp, Coople, \&William, (tanpa tahun:1-2).

Pengembangan seperangkat kegiatan di sentra bermain yang dikembangkan berdasarkan klasifikasi bermain kreatif, yaitu: kreasi terhadap obyek berupa papan alas makanku, gelas cantikku, daftar menuku dan flanel my ice cream; permainan cerita bersambung berupa celemek flanel, big book dan boneka jari; permainan pertanyaan kreatif berupa plastisin sup buah warna warni, flanel aneka buah, kantong pintar; permainan gerak kreatif berupa boneka flanel koki, drawing card; serta permainan drama kreatif berupa miniatur cake, gelas master chef, dan alat makanku.

Berdasarkan temuan penelitian, pada saat anak melakukan kegiatan di sentra bermain peran anak dapat menunjukkan perilaku kreatif dengan memerankan tokoh seolah-olah anak menjadi peran tersebut. Anak menirukan kegiatan yang dilakukan tokoh yang anak mainkan sesuai dengan pengalaman yang pernah mereka lalui. Temuan lapangan tersebut sesuai dengan teori 
menurut Dodge dan Colker (2001) yang mengatakan bahwa bermain peran adalah "The work children do in the house corner is called dramatic play, pretend play, or make-believe it involves taking on a role and engaging in imitative behavior." Artinya anak-anak yang bermain bermain peran disebut dengan bermain drama, bermain pura-pura, atau membuatpercaya, melainkan mengambil peran dan terlibat dalam perilaku imitatif. Selain itu, anak dapat mengemukakan ide untuk suatu kegiatan sesuai dengan pemikiran anak sendiri. Kegiatan-kegiatan yang dilakukan didalam kelas merupakan hasil kesepakatan oleh anak. Kreativitas merupakan suatu proses mental yang dilakukan individu berupa gagasan ataupun produk baru, atau mengkombinasikan antara keduanya yang pada akhirnya akan melekat kepada dirinya. Dengan terpola untuk dapat mengemukakan pendapat, anak menjadi terlatih untuk selalu berbicara tentang ide yang mereka miliki.

Awalnya inisiatif anak, rasa ingin tau anak kurang berkembang secara optimal, setelah dilakukan tindakan kini anak sudah dapat melakukan kegiatan dengan inisiatifnya sendiri, memiliki rasa ingin tahu terhadap hal-hal yang disampaikan guru. Hal ini sesuai awalnya inisiatif anak, rasa ingin tau anak kurang berkembang secara optimal, kini anak sudah dapat melakukan kegiatan dengan inisiatifnya, memiliki rasa ingin tahu. Berdasarkan pengalaman main di sentra yang dialami, anak terlihat sudah mampu memberikan ide-ide dalam kegiatan pembelajaran yang dilakukan. Dari pengalaman tersebut, anak dapat menyelesaikan masalah-masalah sederhana, seperti saat sedang bermain, jika anak mengalami masalah dengan temannya, anak sudah dapat menyelesaikan masalahnya sendiri.

Hal tersebut tidak terlepas dari dimensi proses dan dorongan. Temuan lapangan tersebut sesuai dengan teori menurut Munandar (2009:59), yaitu kreativitas merupakan kemampuan untuk menciptakan sesuatu yang baru, sebagai kemampuan untuk memberikan gagasan-gagasan baru 
Pengembangan Model Kegiatan Sentra... Yuliani \& Trias

yang diterapkan dalam pemecahan masalah.

Hasil penelitian ini dapat memberikan informasi bahwa salah satu cara meningkatkan kreativitas anak adalah melalui kegiatan bermain peran. Kegiatan bermain peran yang melalui proses memberikan kesempatan kepada anak untuk mengutarakan idenya, dengan selalu memberikan dorongan kepada anak, dan tidak lepas dari dorongan yang ada di dalam diri anak untuk menghasilkan sesuatu dari pemikiran anak sendiri. Sesuai catatan lapangan, catatan dokumentasi, dan catatan wawancara dapat ditemukan bahwa dengan kegiatan bermain peran kreativitas anak semakin meningkat.

\section{KESIMPULAN DAN SARAN}

Berdasarkan rumusan tujuan dan hasil yang diperoleh dalam penelitian dan pengembangan kreativitas anak usia dini pada sentra bermain di Provinsi DKI Jakarta, maka disimpulkan, sebagai berikut:

Pertama, pengembangan model konseptual sentra bermain bagi anak usia dini telah sesuai dengan fokus utama yaitu pengembangan kegiatan di sentra bermain. Artinya, melalui sentra bermain telah dikembangkan ini sejumlah karakteristik program kegiatan bermain telah dapat terlaksana sesuai prosedur pengembangan kurikulum bagi anak usia dini.

Kedua, pengembangan desain sentra bermain bagi anak usia dini yang merupakan implementasi dan pengembangan secara konkrit dari model konseptual sentra bermain yang telah dikembangkan juga telah sesuai dengan tahapan pengembangan program kegiatan pembelajaran di sentra bermain, yaitu: pengembangan proyek tema, pengembangan keterpaduan tema dan klasifikasi bermain kreatif, pengembangan tema dan indikator, pengembangan materi berupa bahan belajar dan bermain, pengembangan desain dan produk media gelaran sentra, pengembangan asesmen perkembangan dan pengembangan strategi pembelajaran

Ketiga, pengembangan seperangkat kegiatan di sentra bermain yang dikembangkan 
berdasarkan klasifikasi bermain kreatif, yaitu: kreasi terhadap obyek; permainan cerita bersambung; permainan pertanyaan kreatif; permainan gerak kreatif; serta permainan drama kreatif.

$$
\text { Berdasarkan simpulan }
$$

penelitian diatas, penelitian ini memberikan saran dan rekomendasi sebagai berikut:

Pertama, dengan ditemukannya fakta bahwa kegiatan pada sentra bermain ini ternyata mampu meningkatkan kreativitas anak serta memberikan kontribusi yang berarti terhadap proses pembelajaran anak usia dini, maka disarankan bagi guru yang hendak menggunakan dan menerapkan model pembelajaran sentra bermain ini perlu memiliki pemahaman komprehensif terhadap seperangkat pedoman dan tahapan kerja, sehingga kesalahan-kesalahan yang mungkin terjadi dalam pelaksanaan model di lapangan dapat dihindari. Kedua, upaya yang dapat dilakukan guru agar dapat menggunakan dan menerapkan kegiatan pada gelaran sentra bermain ini dengan sukses. Ketiga, upaya yang dapat dilakukan oleh pihak penyelenggara pendidikan anak usia dini yang memberikan layanan pada anak dengan usia yang sama dalam penelitian ini. Keempat, mengingat keterbatasan penelitian ini, maka untuk mendapatkan hasil yang lebih baik perlu diadakan studi lanjutan tentang kelebihan dan kekurangan dari rancangan model pengembangan ini dan untuk melihat keefektifannya di lapangan dengan menggunakan obyek penelitian yang lebih besar dan variasi agar didapat hasil yang lebih representatif dan memiliki keterdekatan dengan kenyataan di lapangan.

\section{DAFTAR PUSTAKA}

Bennett, William J Chester E, Finn Jr dan John T.E. Cribb, Jr. The Educated Child: a parent's guide. New York: The Free Press. 1999

Borg WR \& Gall MD. Educational Research. New York: Longman. 1983.

Bredekamp, Sue, Couple dan William. (1998). DAP in Early Childhood Programs Serving Children from Birth through Age 8. Washington, DC: NAEYC.

Catron, Carol. E dan Allen, Jan (1999). Early Childhood Curriculum: A Creative Play Model, 2nd Edition. NewJersey: Merill Publ. 
Pengembangan Model Kegiatan Sentra... Yuliani \& Trias

Decker, Anita dan John Decker. Planning and Administering Early Childhood Program 7th Edition. Ohio: Prentice Hall, Inc. 2001.

Diane, E Papalia, Sally Wendkos Old, \& Ruth Duskin Feldman. Human Development. Jakarta: Kencana Prenada Media Group, 2008.

Dick, Walter dan Carey, Lou. The Systematic Design of Instruction 2nd ed. Illinois: Scott, Foresman and Company. 1989.

Dodge, Diane Trister \& Laura J. Colker. The Creative Curriculum for Preschool. Washington DC: Teaching Strategies. 2001.

Duffy, Bernadette. Supporting Creativity and Imagination In The Early Year. New York: Open University Press. 2008.

Gordon, Ann Miles and Kathryn Williams Browne. Beginning and Beyond: Foundations in Early Childhood Education. New York: Delmars Publishing Inc. 1985.

Hughes, Fergus P. Children, Play, and Development. United States of America: SAGE. 2010.

Kitano, Margie K. dan Darrell F. Kirby. Gifted Education: A Comprehensive View. Boston/Toronto: Litt le, Brown and Company. 1986

Lee, Catherine. Pertumbuhan dan Perkembangan Anak. Jakarta: Arcan. 1989.
Mayesty, Mary. Creative Activities for Young Children $4^{\text {th }}$ Ed: Play, Development, and Creativity. New York: Delmar Publishers Inc., 1990.

Morrison, George S. Dasar-Dasar Pendidikan Anak Usia Dini (PAUD). Jakarta: Indeks. 2012.

Munandar, Utami. Pengembangan Kreativitas Anak Berbakat. Jakarta: Rineka Cipta. 2009.

Nurani, Yuliani. Konsep Dasar Pendidikan Anak Usia Dini. Jakarta: Indeks. 2009.

Nurani, Yuliani. Kurikulum Anak Usia Dini. Modul PAUD. Jakarta: Universitas Negeri Jakarta. 2014.

Nurani, Yuliani. dkk. Bermain Kreatif Berbasis Kecerdasan Jamak. Jakarta: Indeks. 2010.

Suparman, Atwi. Desain Instruksional. Jakarta: Proyek Pengembangan Universitas Terbuka, Dirjen Dikti, Depdiknas.

Laporan PPL Mahasiswa S1 PG PAUD Fakultas Ilmu Pendidikan Universitas Negeri Jakarta, 2016. 